To be published in "Journal of global operations and strategic sourcing", which should be cited to refer to this work.

DOI : $10.1108 / J G O S S-11-2020-0069$

\title{
Sustainable partner selection for Collaborative Networked Organisations with risk consideration in the context of COVID-19
}

\author{
Yvonne Badulescu a,b, Ari-Pekka Hameri a and Naoufel Cheikhrouhou ${ }^{b}$ \\ ${ }^{a}$ Faculty of Business and Economics, University of Lausanne, 1015 Lausanne, Switzerland \\ ${ }^{\mathrm{b}}$ Geneva School of Business Administration, University of Applied Sciences and Arts Western Switzerland, HES-SO,
}

Geneva, Switzerland

\section{Structured Abstract}

Purpose: Collaborative Networked Organisations (CNO) are a means of ensuring longevity and business continuity in the face of a global crisis such as COVID-19. This paper presents a multicriteria decision making method for sustainable partner selection based on the three sustainability pillars and Risk.

Design/methodology/approach: A combined Analytic Hierarchy Process (AHP) and Fuzzy Analytic Hierarchy Process with Technique for Order of Preference by Similarity to Ideal Solution (TOPSIS) approach to evaluate and rank potential partners based on known conditions and predicted conditions at a future time based on uncertainty to support sustainable partner selection.

Findings: It is integral to include Risk criteria as an addition to the three Sustainability pillars: economic, environmental, and social, to build a robust and sustainable CNO. One must combine the AHP and Fuzzy-AHP weightings to ensure the most appropriate sustainable partner selection for the current as well as predicted future period.

Originality: The paper presents a novel approach to the partner selection process for a sustainable CNO under current known conditions and future uncertain conditions, highlighting the risk of a force majeure occurring such as COVID.

Research implications: The approach proposed in the paper is intended to support existing CNO, as well as individual firms wanting to create a CNO, to build a more robust and sustainable partner selection process in the context of a force majeure such as COVID-19.

Keywords: Partner Selection, Sustainability, Risk, AHP, Fuzzy AHP, TOPSIS

\section{Introduction}

The global COVID-19 pandemic has made a serious impact on supply chains worldwide in the physical movement of raw materials and goods, lack of materials for production and availability of production capacities around the world. Moreover, economic lockdowns from major global economies have contributed to supply chain disruptions, which have been experienced by $94 \%$ of the Fortune 1000 companies in the United States alone (Accenture, 2020). Furthermore, small to medium sized enterprises (SMEs), making up over $99 \%$ of all companies in Europe, have been particularly impacted in their supply continuity due to the global pandemic (Juergensen et al., 2020). This may be attributed to the lack of the necessary skills and bargaining power with suppliers needed to respond to the quickly changing requirements (Crispim and Pinho de Sousa, 2009; Mun et al., 2009).

Collaborative Networked Organisations (CNO) can better respond to rapid changes in the face of global disasters such as global health pandemics, as well as economic or environmental crises. Sustainable partner selection considering risk is important in ensuring the resilience of the CNO in the context of a global pandemic such as COVID-19, however, the problem is that the existing partner selection processes for $\mathrm{CNO}$ have focused mainly on past economic performance alone. As seen from the global COVID pandemic, past economic performance of companies has not been an indicator of longevity and resilience in times of crisis. It is therefore integral to consider all the pillars of sustainability: economic, environmental, and social, as well as the corresponding risks of partnership in the sustainable partner selection process for CNO. Furthermore, the current methods in partner selection disregard the evolution of criteria over time which could 
incite the alliance to fail due to the non-static importance of criteria over the lifecycle of the CNO. Therefore, this paper proposes to evaluate the partners based on criteria for the current known conditions as well as the predicted future conditions. Regarding the importance of the evolution over time, the lifecycle of the CNO can be extended based on what the partnership could become, particularly in the case of a global pandemic, not only based on its current situation.

This paper aims to find a solution for the supply chains of $\mathrm{CNO}$ to be more resilient in the face of large-scale disruptions stemming from force majeure such as a global pandemic. Joining a CNO increases the collective capabilities and capacity of its partners, therefore the purpose of this paper is to present a novel approach for the sustainable partner selection for a resilient CNO in the face of global pandemics and acts of god. The proposed methodology combines both current and future economic, environmental, social and risk conditions, to account for the evolution in perceived importance of evaluation criteria over time. A case study demonstrates the significance of integrating risk criteria in partner selection and combining the criteria evaluation under current and future conditions. The approach for partner selection in $\mathrm{CNO}$ is based on a multi-criteria decision-making method integrating sustainability and risk criteria for the existing and future scenarios.

The rest of this paper is organised as follows: In the next section, a literature review is presented followed by the methodology on the problem of sustainable partner selection in $\mathrm{CNO}$ focusing on sustainability and risk criteria in section 3. A case study is presented, and the results are discussed in section 4 followed by managerial implications in section 5. Finally, section 6 concludes the paper and some perspectives for further research are proposed.

\section{Literature Review}

To ensure sustainability and longevity as well as maintainable agility in times of crisis, individual companies must seek to improve their own capabilities as well as to pursue cooperation with other organisations with complimentary competencies by joining a CNO (Camarinha-Matos et al., 2009). CNO have allowed companies to continue satisfying customer demands in highly volatile environments (Sarkis et al., 2007). The relevant literature covers several domains, specifically, the partner selection problem, sustainability criteria in $\mathrm{CNO}$, multi-criteria decision-making (MCDM) approaches for $\mathrm{CNO}$ partner selection that include uncertainty, and the inclusion of risk factors in $\mathrm{CNO}$ partner selection.

Talluri and Baker (1996) consider the cost, time and distance between partners to solve the partner selection problem in Virtual Corporations (VC) using a two-phase mathematical programming approach. Wu and Su (2005) focus on manufacturing cost minimisation and shortest production lead-time for the partner selection problem in Virtual Enterprises (VE) and develop an Integer Programming (IP) formulation to find the solution. Choudhary et al. (2019) apply text analysis and link analysis to tender documents to identify knowledge of potential partners for a $\mathrm{CNO}$ and Ben Salah et al. (2020) integrate the negotiation process into the partner selection problem for VE looking for temporary partners to work on short projects.

Multi-criteria decision-making (MCDM) approaches are considered more appropriate methods of solving the partner selection problem than pure mathematical methods (Mikhailov, 2002). Huang et al. (2010) propose an approach based on Multi-Objective Programming (MOP) to solve the partner selection problem in strategic alliances and the corresponding resource allocations by incorporating synergies between objectives. Sarkis et al. (2007) develop a framework using the Analytic Network Process (ANP) method for Agile VE partner selection. Chen et al. (2008) use the ANP approach to treat the partner selection problem by adapting the relative weights of criteria according to the priority of motivations to establish strategic alliances. Arrais-Castro et al. (2015) develop a collaborative negotiation platform that supports the selection of business partners and suppliers with changeable temporal parameters taking into account past, present and future data, using dynamic MCDM and an information fusion method for evaluation. Ben Salah et al. (2020) review the state of the art on the criteria selection when using an MCDM approach in partner selection for $\mathrm{CNO}$ in which no environmental or social factors are mentioned. However, Wu and Barnes (2016) take environmental factors into account and use ANP and MOP to solve the green partner selection and supply chain construction problem. Verdecho et al. (2010) develop an ANP approach to select suppliers, also adding sustainability criteria to the balanced scorecard method, to support the sustainability of a CNO. Bhattacharya et al. (2020) apply analytic hierarchy process (AHP) and Technique for Order Preference by Similarity to Ideal Solution (TOPSIS) for partner selection in the textile industry and found that cost, environmental management, and human rights were the most important evaluation criteria. 
Moreover, several papers treat the partner selection problem by also taking uncertainty into account. Huang et al. (2011) base their Particle Swarm Optimisation (PSO) algorithm on vague sets in the formation of a VE under uncertain information. Tan and Zhang (2006) present a Multi Attribute Decision making (MADM) method based on Intervalvalued Intuitionistic Fuzzy Sets (IVIFSs) theory and TOPSIS method to deal with uncertainty. Chen and Tsao (2008) use Interval-Valued Fuzzy Sets in TOPSIS and extend it to the partner selection problem. Polyantchikov et al. (2017) use AHP, TOPSIS and fuzzy set theory to develop a decision-making tool for partner selection for rapid formation of VE. Luo et al. (2008) propose an MADM approach for partner evaluation of the agile supply chain based on a method that combines AHP and Fuzzy comprehensive evaluation (FCE) to avoid the effect of uncertainty in expert judgments. Kafa et al. (2015) establish an integrated approach based on Fuzzy AHP, and Preference Ranking Organisation Method for Enrichment of Evaluations (PROMETHEE) for partner selection in the context of closed-loop supply chain network configuration.

When it comes to Multi-Criteria Group Decision-Making Techniques (MCGDM) in a Fuzzy environment, Ye (2010) presents an Interval Valued Intuitionistic Fuzzy (IVIF) TOPSIS method to solve the problem of partner selection in VE under uncertain and unknown information. Garg and Sharma (2020) use a combined model to select suitable outsourcing partners for a supply chain based on best-worst method (BWM) and Vlsekriterijumska Optimizacija I Kompromisno Resenje (VIKOR) approaches. Mikhailov (2002) use a Fuzzy Preference Programming (FPP) model for the partner selection problem under incomplete information environment in VE based on fuzzy set theory to which Wang and Chen (2007) apply consistent Fuzzy preference relations. Crispim and Pinho de Sousa (2009) develop a tool for VE partner selection using Case-Base Reasoning, Multi-objective Tabu search, and Fuzzy TOPSIS. Rani et al. (2020) focus on environmental sustainability and propose a solution for the selection of recycling partners by extending the Pythagorean Fuzzy TOPSIS Method under uncertainty. Ashtiani et al. (2009) use an IVF-TOPSIS method to solve MCGDM problems with unequal criteria weights. Ayadi et al. (2013) propose an extensive method to select partners in CNO using a Fuzzy AHP-TOPSIS approach. Yue (2013) presents a MCGDM technique for partner selection problem in a new VE with linguistic values and intuitionistic fuzzy information. Ashayeri et al. (2012) use an Intuitionistic Fuzzy Choquet integral operator MCGDM approach to select the right partners and establish the right configuration in a supply chain. Ye and Lin (2014) propose another extension to TOPSIS for MCGDM with weighted possibilistic mean values for the partner selection problem in VE. The review of the literature shows the many methods used to tackle the partner selection problem under defined conditions and constraints using crisp values, and under uncertainty using fuzzy approaches. Table 1 provides a summary of the methods used for partner selection in different contexts as well as the evaluation criteria considered.

Most of the abovementioned research was meant to solve the partner selection problem in different forms of collaboration: Virtual Organisations (VO), VE or Agile Supply Chains. However, as far as our literature review goes, the papers treating the subject of $\mathrm{CNO}$ in general remain rare, particularly related to the sustainability of $\mathrm{CNO}$ from an environmental, economic, social and risk points of view. From a sustainability perspective, the purpose of a CNO is mainly to overcome internal limitations in the individual entities and to boost capabilities and organisational capacities (Kapucu et al., 2012). Quarantelli et al. (2007) argue that collaboration between organisations is an essential element in sustainability particularly in the face of unforeseeable disastrous events. Jung (2017) uses the international collective action framework to study the effect of inter-organisational collaboration to ensure business continuity during and after global disasters. They argue that collaboration between organisations is indispensable to their resilience as they can more easily secure required resources to continue operations. Leading the research for the integration of sustainability in partner selection in supply chains is Wittstruck and Teuteberg (2012) which develop a Fuzzy AHP-TOPSIS approach for selecting recycling supply chain partners based on financial, environmental and social criteria. Memari et al. (2019) propose a multi-criteria intuitionistic fuzzy TOPSIS method for sustainable supplier selection to account for the uncertainty in judgement. Jia et al. (2015) apply TOPSIS for sustainable supplier selection to the highly unsustainable global fashion industry. Zimmer et al. (2016) perform a detailed literature review of the methods and criteria considered for sustainable supplier selection and identify the $28 \%$ of the literature up to the date of analysis consider the three pillars of sustainability, however, mention that only the economic risks are taken into account, not the risks associated with society or environment. When looking more closely at partner selection for CNO, Xiao et al. (2016) use Improved Gravitational Search Algorithm (I-GSA) and PSO to solve the problem of Green Partner Selection in VE. Zhang et al. (2013) use a Pareto Genetic Algorithm to select Green partners in the electronics industry in a VE, taking into account two green criteria: Carbon emission and lead content. Although sustainable partner selection has been deeply researched in supply chains, the concept of developing sustainable CNO based on the three pillars of sustainability: economic, environmental and social factors, as well as risk, has not been investigated in detail. 
Table 1: Overview of the state of the research concerning the partner selection problem including risk and uncertainty.

\begin{tabular}{|c|c|c|c|c|c|c|c|}
\hline \multirow[b]{2}{*}{ Reference } & \multirow[b]{2}{*}{ Method } & \multirow[b]{2}{*}{ Context } & \multicolumn{5}{|c|}{ Features considered } \\
\hline & & & $\stackrel{\check{u}}{\ddot{n}}$ & 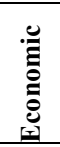 & 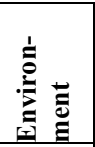 & 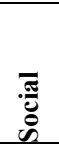 & 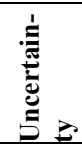 \\
\hline Arrais-Castro et al. (2015) & Dynamic MCDM and information fusion method & Supply Chain & & $\mathrm{x}$ & & & $\mathrm{x}$ \\
\hline Ashayeri et al. (2012) & Intuitionistic Fuzzy Choquet integral operator & Supply Chain & & $\mathrm{x}$ & & & $\mathrm{x}$ \\
\hline Ashtiani et al. (2009) & IVF-TOPSIS & Method for uncertainty & & & & & $\mathrm{x}$ \\
\hline Ayadi et al. (2013) & Fuzzy AHP - TOPSIS & Supply Chain & $\mathrm{x}$ & $\mathrm{x}$ & & $\mathrm{x}$ & $\mathrm{x}$ \\
\hline Bhattacharya et al. (2020) & AHP-TOPSIS & Supply Chain & & $\mathrm{x}$ & $\mathrm{x}$ & $\mathrm{x}$ & \\
\hline Chen and Tsao (2008) & Interval-Valued Fuzzy Sets & Method for uncertainty & & & & & $\mathrm{x}$ \\
\hline Chen et al. (2008) & Analytic Network Process (ANP) & Strategic partner selection & & $\mathrm{x}$ & & $\mathrm{x}$ & \\
\hline Choudhary et al. (2019) & Text analysis and link analysis & Virtual Organisations & & & & $\mathrm{x}$ & \\
\hline Crispim and de Sousa (2009) & Case-Base Reasoning, Multi-objective Tabu search, and Fuzzy TOPSIS & Virtual Enterprise & & $\mathrm{x}$ & & $\mathrm{x}$ & $\mathrm{x}$ \\
\hline Dinu and Pacuraru, 2011 & Genetic algorithm & Virtual Organisations & $\mathrm{x}$ & $\mathrm{x}$ & & & \\
\hline Garg and Sharma (2020) & BWM and VIKOR & Supply Chain & & $\mathrm{x}$ & $\mathrm{x}$ & $\mathrm{x}$ & \\
\hline Huang et al. (2010) & Multi-Objective Programming (MOP) & Strategic partner selection & & $\mathrm{x}$ & & & \\
\hline Huang et al. (2011) & Particle Swarm Optimisation (PSO) algorithm & Method for uncertainty & & $\mathrm{x}$ & & & $\mathrm{x}$ \\
\hline Ip et al. (2003) & Rule-based genetic algorithm embedded project planning knowledge & Virtual Enterprise & $\mathrm{x}$ & $\mathrm{x}$ & & & \\
\hline Jia et al. (2015) & TOPSIS & Supply Chain & & $\mathrm{x}$ & $\mathrm{x}$ & $\mathrm{x}$ & \\
\hline Kafa et al. (2015) & Fuzzy AHP, and PROMETHEE & Supply Chain & & $\mathrm{x}$ & $\mathrm{x}$ & $\mathrm{x}$ & $\mathrm{x}$ \\
\hline Luo et al. (2008) & AHP and Fuzzy comprehensive evaluation (FCE) & Supply Chain & & $\mathrm{x}$ & & & $\mathrm{x}$ \\
\hline Macedo \& Camarinha-Matos(2017) & V-Align Framework to align common values & Virtual Organisations & $\mathrm{x}$ & & & & \\
\hline Memari et al. (2019) & Multi-criteria intuitionistic fuzzy TOPSIS & Supply Chain & & $\mathrm{x}$ & $\mathrm{x}$ & $\mathrm{x}$ & \\
\hline Mikhailov (2002) & Fuzzy Preference Programming (FPP) model & Virtual Enterprise & & $\mathrm{x}$ & & & $\mathrm{x}$ \\
\hline Polyantchikov et al. (2017) & AHP, TOPSIS and fuzzy set theory & Virtual Enterprise & & $\mathrm{x}$ & & & $\mathrm{x}$ \\
\hline Rani et al. (2020) & Pythagorean Fuzzy TOPSIS Method & Supply Chain & & $\mathrm{x}$ & $\mathrm{x}$ & & $\mathrm{x}$ \\
\hline Sarkis et al. (2007) & Analytic Network Process (ANP) & Virtual Enterprise & & $\mathrm{x}$ & & & \\
\hline Talluri and Baker (1996) & Two-phase mathematical programming approach & Virtual Enterprise & & $\mathrm{x}$ & & & \\
\hline Tan and Zhang (2006) & IVIFSs theory and TOPSIS & Method for uncertainty & & & & & $\mathrm{x}$ \\
\hline Verdecho et al. (2010) & ANP and balanced scorecard method & Supply Chain & & $\mathrm{x}$ & $\mathrm{x}$ & $\mathrm{x}$ & \\
\hline Wang and Chen (2007) & FPP with Fuzzy preference relations & Virtual Enterprise & & $\mathrm{x}$ & & & $\mathrm{x}$ \\
\hline Wittstruck \& Teuteberg (2012) & Fuzzy-AHP TOPSIS & Supply Chain & & $\mathrm{x}$ & $\mathrm{x}$ & $\mathrm{x}$ & \\
\hline Wu and Barnes (2016) & ANP and MOP & Supply Chain & & $\mathrm{x}$ & $\mathrm{x}$ & & \\
\hline $\mathrm{Wu}$ and $\mathrm{Su}(2005)$ & Integer Programming (IP) formulation & Virtual Enterprise & & $\mathrm{x}$ & & & \\
\hline Xiao et al. (2016) & Improved Gravitational Search Algorithm (I-GSA) and PSO & Virtual Enterprise & & $\mathrm{x}$ & $\mathrm{x}$ & $\mathrm{x}$ & \\
\hline Ye (2010) & Interval Valued Intuitionistic Fuzzy (IVIF) TOPSIS & Virtual Enterprise & & $\mathrm{x}$ & & & $\mathrm{x}$ \\
\hline Ye and Lin (2014) & TOPSIS & Virtual Enterprise & & $\mathrm{x}$ & & & $\mathrm{x}$ \\
\hline Yue (2013) & Projection technique & Virtual Enterprise & & $\mathrm{x}$ & & & $\mathrm{x}$ \\
\hline Zhang et al. (2013) & Pareto Genetic Algorithm & Virtual Enterprise & & $\mathrm{x}$ & $\mathrm{x}$ & & \\
\hline Zhao et al. (2008) & PSO algorithm & Virtual Enterprise & $\mathrm{x}$ & $\mathrm{x}$ & & & \\
\hline
\end{tabular}


The concept of risk in partner selection has been considered in some papers however the type of risk, besides project management risks, have not been so far considered. Zhao et al. (2008) establish a PSO algorithm for the partner selection problem in VE for projects with precedence and due date constraints. Ip et al. (2003) consider risk factors and project due dates in the selection of partners for a VE. Their "risk-based partner selection problem" is solved using a rule-based genetic algorithm with embedded project planning knowledge. Dinu and Pacuraru (2011) also develop a genetic algorithm to solve the multi-objective partner selection problem in VO considering the operational and partnership costs, the reaction lead-time to market of each partner, and the risk of running each enterprise; however, the types of risks are undefined. Abreu and Camarinha-Matos (2008) identify the importance of common value systems for risk reduction and long term sustainability in CNO and Macedo and Camarinha-Matos (2017) develop an approach to analyse the alignment of value systems in the creation of $\mathrm{VO}$ in order to reduce collaboration risks. However, none of the papers consider the risks associated with selecting partners in the face of a crisis-like scenario such as COVID-19.

\section{Methodology}

We propose a new approach to select the best partner for a CNO from sustainability and risk points of view. The method takes into consideration the current context and known constraints, as well as the uncertainty related to the role of the partner in the case of a probable disaster scenario in the future. This method combines the features of the AHP method, Fuzzy Sets theory, and TOPSIS. We consider the problem of selecting a partner among several candidates to join an existing $\mathrm{CNO}$, which focuses on the three pillars of sustainability: environmental, social and economic; and risk.

The methodology, illustrated in Figure 1, has three phases: the preparation phase, determining criteria weights and the TOPSIS phase for final ranking of the potential partners. Phase 1 consists of establishing a team of decision-makers (DM) which have the responsibility of identifying the potential partners being evaluated to join the CNO, determining the sustainability and risk criteria to be used to evaluate the potential partners, and comparing the criteria pairwise to determine prioritisation and weights, which is Phase 2.

The sustainability and risk criteria in this paper have been gathered from literature and defined based on the current COVID-19 crisis and are presented and described in Table 2. The chosen criteria to evaluate the problem are classified hierarchically. The weights are determined for the criteria at each hierarchical level using Saaty's pairwise comparison starting at the top and then translated to lower levels. The weights at each level must add up to 1 . The level of risk is measured based on the probability the event will occur and the severity of the impact of the event. The risks mentioned in the criteria include risks associated with the CNO partnership except for the Force Majeure Risk. The Force Majeure Risk includes unforeseeable disasters in the future such as in the case of the global COVID-19 pandemic and its worldwide effects. Unlike the other risk criteria in which the probability of occurrence and their impact can be mitigated by the CNO partners themselves with a risk mitigation plan, the probability of occurrence of a force majeure is completely out of the control of the $\mathrm{CNO}$ and its partners. That being said, the $\mathrm{CNO}$ and its partners can determine a business continuity plan in the occurrence of such an event thereby partially mitigating its impact by collaborating together and combining resources.

Phase 2 consists of the process to determine the criteria weights using a combination of the weights from the AHP and Fuzzy-AHP approaches. The AHP process is used to determine the weights of the criteria based on an evaluation by the experts under the known conditions of today. In addition, AHP is a useful method for modelling the sustainable partner selection problem for a $\mathrm{CNO}$ since it allows deriving priorities among criteria considering their hierarchal structure. Firstly, the experts and decision-makers perform pairwise comparison using the Saaty 1-9 scale between firstly the highest level of criteria: economic, social, environmental and risk, followed by pairwise comparison of the criteria in each of those pillars and finally the sub-criteria to create a pairwise comparison matrix $(A)$. The normalised weight vector $(w)$ is then obtained by determining the maximum eigenvalue $\lambda_{\max }$ of the comparison matrix $(A)$ and finding the solution to Eq. (1).

$$
A w=\lambda_{\max } w
$$




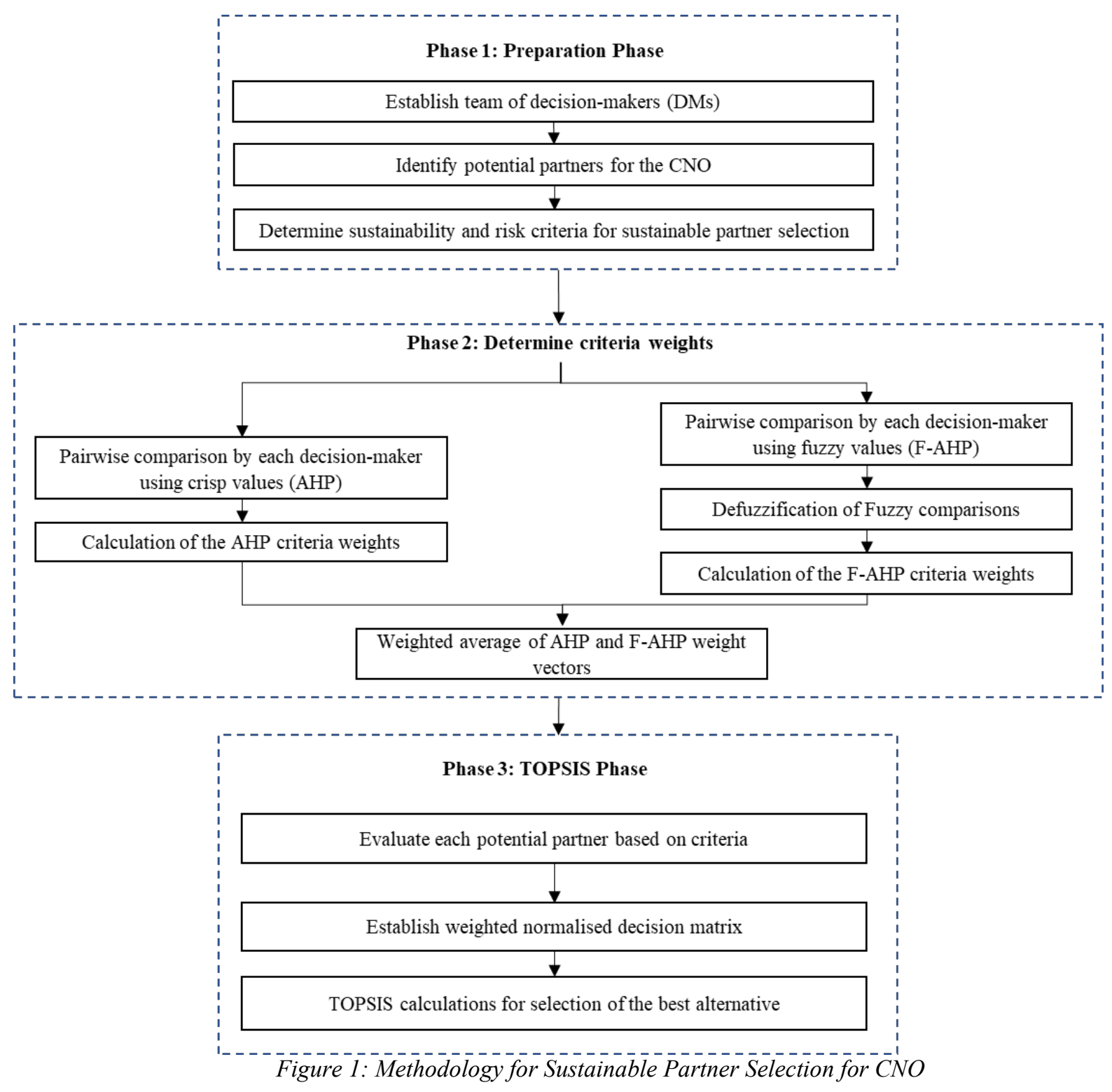

Table 2: Sustainability and Risk Criteria for Sustainable Partner Selection for CNO

\begin{tabular}{|c|c|c|c|c|}
\hline & Criteria & Sub criteria & Description & Reference \\
\hline \multicolumn{5}{|l|}{ Social } \\
\hline \multicolumn{5}{|c|}{ Employee thriving } \\
\hline & & Employment & This criterion assesses the level of employee & (Cheikhrouhou et al., \\
\hline & & training & training. & \\
\hline & & $\begin{array}{l}\text { Internal } \\
\text { Information }\end{array}$ & $\begin{array}{l}\text { Level of knowledge transparency between } \\
\text { employees inside the firm. }\end{array}$ & (Spreitzer et al., 2012) \\
\hline & & Sharing & & \\
\hline & & $\begin{array}{l}\text { Performance } \\
\text { feedback }\end{array}$ & Frequency of feedback for performance. & (Spreitzer et al., 2012) \\
\hline & & Civility & $\begin{array}{l}\text { This criterion addresses the employee's behaviour } \\
\text { between each other and the partner's employees. }\end{array}$ & $\begin{array}{l}\text { (Cheikhrouhou et al., } \\
\text { 2013) }\end{array}$ \\
\hline & & $\begin{array}{l}\text { Workplace } \\
\text { conditions }\end{array}$ & $\begin{array}{l}\text { This criterion rates the state of the workplace and the } \\
\text { preventive measure that the firm uses to avoid harm. }\end{array}$ & \\
\hline & Qualifica & on of employees & Evaluation of the employee's education level. & (Cheikhrouhou et al., \\
\hline
\end{tabular}


Employee retention

Community impact

Bribery and corruption

Employee insurance

Culture

Stakeholder's trust

\section{Environment}

Energy management

Environmental accidents and remediation

Waste management

Environment government requirement

Environmental lifecycle
The average time that employees remain in the firm.

This criterion assesses the effect that the $\mathrm{CNO}$ could have on the surrounding social environment.

This criterion assesses the honesty of the potential partner regarding the stakeholders and which way it use for attaining it objective

This criterion assesses if all employees of the firm are appropriately insured.

This criterion is about the culture fit between companies. This criterion has a great influence on the partnership duration.

The level of trust of employees, customers, shareholders, and suppliers have with the company.

The process of optimising energy consumption and improvement of energy efficiency.

The history of the partner's past issues and how they were corrected.

The management of waste from creation to disposal.

This is the environmental policy led by the government that the $\mathrm{CNO}$ must apply.

This criterion assesses the environmental impact such as greenhouse gas emissions.

\section{Economic}

Information sharing

Long term viability of the core business

$\mathrm{R} \& \mathrm{D}$ investment

Collaborative complementarity

Property--based
resources
Strategic
correspondence

Access to a

Market channel

Knowledge

Quality certification

complementarity

Flexibility

Contractual commitment

Proximity

Shared

value
Extent to which the considered partner would communicate and share critical information with the CNO members and with the network coach.

This criterion assesses the financial and economic sustainability of the core business of the partner. This criterion assesses the investment that the firm invests into research and development.

capital and physical resources.

This criterion assesses the objectives alignment between partners.

This criterion assesses the possibility that a partner gives to the alliance to access a new market This criterion assesses the knowledge that a new partner brings to the CNO.

The quality certification represents the certification further to audit, like ISO.

It is the rapidity with which the partner responds to demand.

Level of acceptance of the agreements in the partnership contract.

It corresponds to the geographical distance to the network

The extent of the interdependence to which all partners share common corporate success.
2013; Wu et al., 2009)

(Cummings and

Holmberg, 2012)

("GRI 413: LOCAL

COMMUNITIES

2016," 2018)

("GRI 205: ANTICORRUPTION 2016," 2018)

(Bierly and Gallagher, 2007; Nielsen and

Gudergan, 2012)

(Eccles and Serafeim, 2013; Labuschagne and Brent, 2005)

(Eccles and Serafeim, 2013; Labuschagne and Brent, 2005)

(Eccles and Serafeim, 2013)

(Seuring, 2013)

(Kara et al., 2012)

(Cummings and

Holmberg, 2012;

Labuschagne and Brent, 2005)

(Das and Teng, 2000)

(Macedo and

Camarinha-Matos, 2017; Nielsen and

Gudergan, 2012)

(Chen et al., 2010)

(Chen et al., 2010)

(Abreu and CamarinhaMatos, 2008; Kara et al., 2012)

(Shah and

Swaminathan, 2008)

(Kara et al., 2012)

(Cheikhrouhou et al., 2013) 
Risk

Performance risk
Relational risk
Inequality of shared risk

Knowledge convey risk

Force Majeure Risk

Quality
risk
Customer relationship risk
The potential that the partnership will not deliver as much value as required or expected.

The risk of not having satisfactory cooperation or the risk of the partner behaving opportunistically. The probability and consequence that the various partners will not equally share potential risks thereby creating unequal levels of interest and effort in the partnership.

The risk that one partner takes the knowledge of another and uses it to their own advantage leading to potential emergent competition risk in which the partner dissolves the alliance and become a competitor.

The probability and consequence of an extraordinary event or circumstance beyond the control of the companies occurs (eg. war, strike, epidemic, pandemic and "Acts of God")

The potential for economic losses due to quality that fails to meet the CNO quality goals.

This risk refers to the corporate reputation of the partners which is the overall opinion of the company by its customers based on past actions and probability of their future behaviour, and consequently the impact on the CNO.
(Das and Teng, 2000)

(Abreu and CamarinhaMatos, 2008)

(Casady and Baxter, 2020)

(Camarinha-Matos et al., 2008)

The second part of Phase 2 is to predict the evolution of the criteria weights in the future using a combination of AHP with the Fuzzy Sets theory, Fuzzy AHP (F-AHP), as it takes uncertainty into consideration in the prioritisation calculation. The existing methods in CNO partner selection do not take the evolution of the importance of criteria into account which can potentially lead to the dissolution of the CNO due to the non-static importance of the evaluation criteria in the lifecycle of the CNO. Therefore, F-AHP is proposed to determine the evolution of the criteria weights in the future using fuzzy numbers to attribute predicted weights to the criteria based on the experts' perceived importance. The aim of the proposed method is to consider the evolution of the criteria weights over time. The partner selection criteria are weighted and prioritised based on expert judgment using F-AHP in the presence of uncertainty. F-AHP uses fuzzy sets theory and a hierarchical analysis approach for the selection of a partner. The uncertain nature of the comparison process leads to decision makers expressing interval judgments rather than fixed value judgments (Bozdag et al., 2003). This paper proposes the F-AHP approach using Triangular Fuzzy Numbers (TFNs) on a pairwise comparison scale. We use the extent analysis method to select synthetic extent values of the pairwise comparisons. Please refer to Kara and Cheikhrouhou (2014) for the detailed calculation steps for F-AHP.

Both methods, AHP and F-AHP, determine the weights of the criteria based on current known conditions and predicted criteria weights under the uncertainty of a future context. Therefore, each criterion has two weights, using AHP under known conditions and F-AHP, under uncertainty. The two weights per criterion are averaged (weighted average of $50 \%$ each) to determine a combined criteria weight vector used in Phase 3, which is an approach to rank the potential partners. This is part of the TOPSIS procedure in which the potential partners receive an evaluation per criterion and then multiplied by the combined criteria weight vector to determine the normalised weighted decision matrix. The distance from the ideal best and worst solutions can then be calculated to determine the relative closeness to the ideal solution for each potential partner with which they are finally ranked from closest (best) to farthest (worst).

The TOPSIS approach ranks the potential partners based on their distance from the positive and negative ideal solutions (Hwang and Yoon, 2012). The number of potential partners (j) are denoted as $A_{1}, A_{2}, \ldots, A_{j}$. $f_{i j}$ represents the value of the $i^{\text {th }}$ criterion function for the potential partner $A_{j}$. Assuming that $\mathrm{n}$ is the number of criteria, the TOPSIS procedure consists of the following steps:

Step 1: Determine the normalised decision matrix. Each normalised value $r_{i j}$ is calculated as:

$r_{i j}=\frac{f_{i j}}{\sqrt{\sum_{j=1}^{J} f_{i j}^{2}}}, j=1,2,3 \ldots n$ 
Step 2: Determine the weighted normalised decision matrix. Each weighted normalised value $v_{i j}$ is calculated as:

$v_{i j}=w_{i} * r_{i j} j=1,2,3, \ldots, J$ and $i=1,2,3, \ldots, n$

Where $w_{i}$ is the weight of the $i^{\text {th }}$ criterion and $\sum_{i=1}^{n} w_{i}=1$.

Step 3: Determine the ideal and negative ideal solutions, respectively $A^{*}$ and $A^{-}$.

$A^{*}=\left\{v_{1}^{*}, \ldots, v_{i}^{*}\right\}=\left\{\left(\max _{i} v_{i j} \mid i \in I^{\prime}\right),\left(\min _{j} v_{i j} \mid i \in I^{\prime \prime}\right)\right\}$

$A^{-}=\left\{v_{1}^{-}, \ldots, v_{i}^{-}\right\}=\left\{\left(\min _{j} v_{i j} \mid i \in I^{\prime}\right),\left(\max _{j} v_{i j} \mid i \in I^{\prime \prime}\right)\right\}$

Where $I^{\prime}$ is associated with the benefit criteria, and $I^{\prime \prime}$ is associated with cost criteria.

Step 4: Calculate the distances from the positive and negative ideal solutions using the n-dimensional Euclidean distance. The distance of each potential partner from the positive ideal solution is given as:

$D_{j}^{*}=\sqrt{\sum_{i=1}^{n}\left(v_{i j}-v_{i}^{*}\right)^{2}} \quad \mathrm{j}=1,2,3, \ldots, \mathrm{J}$

Similarly, the distance from the negative ideal solution is given as:

$D_{j}^{-}=\sqrt{\sum_{i=1}^{n}\left(v_{i j}-v_{i}^{-}\right)^{2}} \quad \mathrm{j}=1,2,3, \ldots, \mathrm{J}$

Step 5: Calculate the relative closeness to the ideal solution. The relative closeness of the potential partner $A_{j}$ is defined as:

$C C_{j}^{*}=\frac{D_{j}^{-}}{D_{j}^{*}+D_{j}^{-}} \quad \mathrm{j}=1,2,3, \ldots, \mathrm{J}$

Step 6: Rank the preference order from closest (best) to farthest (worst).

The main advantages in using TOPSIS are that both the ideal and the anti-ideal solutions are taken into consideration, and its ease of programming (Karsak and Kuzgunkaya, 2002) as well as its ease in decision-making and its flexibility (Joshi and Kumar, 2016).

\section{Case Study Results and Discussion}

The proposed methodology is demonstrated on a Swiss CNO called Swiss MicroTech (SMT). SMT is a regional CNO created in 2001 following a study conducted in the late 1990s on SMEs of the mechanical subcontracting sector of Western Switzerland. SMT includes partners from many industries including telecommunications, medical devices, precision machinery and watch making. Around $90 \%$ of SMT products are meant for worldwide export. The two different types of $\mathrm{CNO}$ are vertical, in which the competences of the enterprises that are needed to achieve a business opportunity are complementary, and horizontal $\mathrm{CNO}$, which have close competence fields and are mainly interested in increasing their capacities or their negotiation powers with external parties (Cheikhrouhou et al., 2012). The purpose of the creation of the horizontal CNO, SMT, was that the member companies were considered too small in size to obtain sufficient visibility or contracts with larger companies and customers in their industry. At the time, the smaller companies were competing with larger suppliers that could provide a complete solution to their customers (including engineering, machining, thermal treatment and sometimes assembly) or suppliers in lower cost countries than Switzerland. The problem with most of the SMEs resided in the lack of their commercial services, the long leadtimes and their delivery unreliability. SMT was created by four members in June 2001 aiming to become more competitive on the market which tried to overcome their weaknesses (mainly consisting of reducing their delivery leadtimes and obtain more competitive purchasing prices). Since its creation, the number of the members in the network has varied. The executive board of the CNO is represented by the CEOs of each company and the managing network coach. The role of the coach is to develop the CNO, to ensure that all decisions are taken in a fair way and to manage the financial activities of the network. Between 8 and 10 meetings are organised by the group of decision-makers per year to discuss strategy-related subjects, as well as other decisions and actions. Moreover, the 
meetings include discussions regarding new potential partners to the $\mathrm{CNO}$ as well as the termination of existing members.

The decision of the selection of new partners is taken with a common consensus by the executive board of the CNO, which means that they are easily implemented since the members of the network are not linked by contracts, even if the network organisation is considered as a legal entity.

\subsection{Case Study Results}

The methodology is demonstrated on the sustainable selection of a new partner for the CNO SMT that counteracts the potential risks facing the partnership and particularly the CNO's ability to manage future global disasters, like in the case of the COVID-19 pandemic. There are three potential partners A1, A2 and A3, which are evaluated using 36 sustainability and risk criteria. First, the potential partners are evaluated and ranked based on known information in a stable environment and then based on a predicted future scenario. The two scenarios are combined to establish an average of the criteria weights and a decision regarding the most appropriate partner is made using TOPSIS.

The first step is to give weights to the evaluation criteria using Saaty's prioritisation method at each hierarchical level. The first level is the prioritisation between the sustainability criteria: economic, environmental and social, and the risk criteria. Figure 2 shows the final normalised weights of these criteria under known conditions (AHP) and future uncertain conditions (F-AHP).

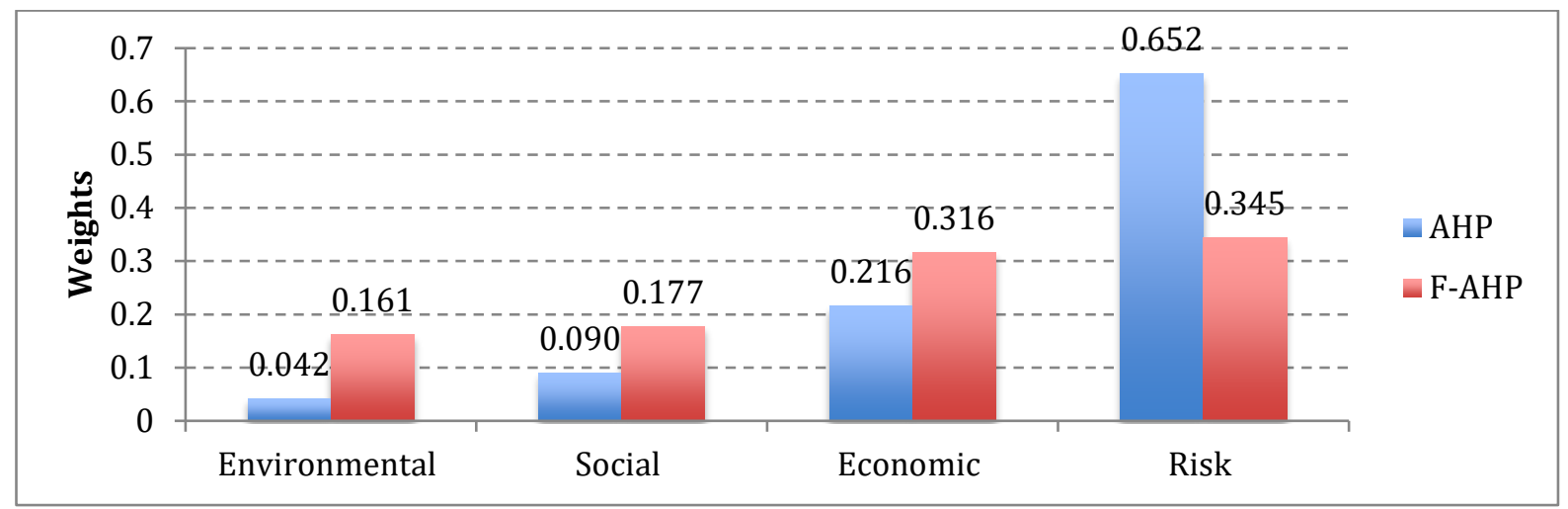

Figure 2: Weights of the sustainability and risk criteria in known current vs. uncertain future scenario (AHP vs. F-AHP)

Once the weights of the criteria are calculated using the AHP method for the known scenario and F-AHP for the future scenario under uncertainty, they are combined using an average and the potential partners must be evaluated based on each of the criteria. The potential partners are evaluated per criteria and given a score between 1 (very poor) to 5 (very good). Figure 3 shows the scores of the potential partners per criterion. The x-axis is the list of the 36 sustainability and risk evaluation criteria, followed by their normalised weights per criterion, which is calculated in Phase 2 . The weights of the 36 criteria add up to 1 . The y-axis represents the score, 1 (worst) to 5 (best), that each of the potential partners (A1, A2 and A3) are given per criterion. For example, the first criterion, R\&D investment, has a weight of 0.017 . The potential partners, A1, A2 and A3, all have been given a score of 4 out of 5 for this criterion, and therefore considered all as good as each other in terms of R\&D investment. However, the last criterion on the $\mathrm{x}$-axis, Force Majeure Risk, which has a weight of 0.076 , shows that A1, with a score of 5 , outperforms A2, with a score of 4 , which in turn outperforms A3, with a score of 3, in this criterion. It can be seen from Figure 2 that the evaluation scores of the potential partners per criterion does not intuitively show which potential partner is best to select for the CNO. Therefore, each score is multiplied by the corresponding criteria weights and then the normalised matrix is computed. Then, the TOPSIS approach is used to determine the distances from both the positive and negative ideal solutions and finally to rank the potential partners based on the relative closeness from the ideal solution. The relative closeness and ranking of potential partners are shown in Table 7. 


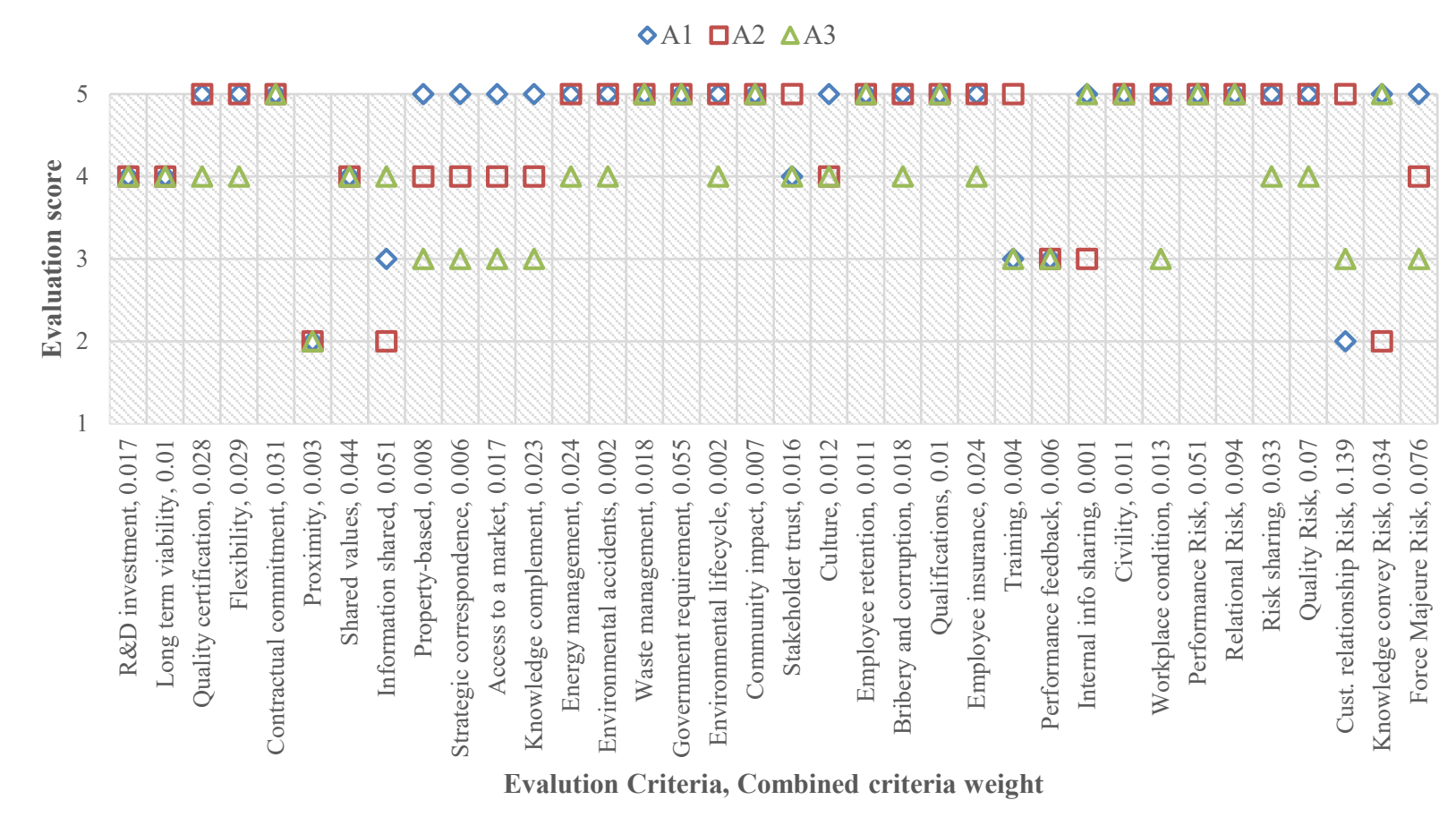

Figure 3: Combined normalised weights of evaluation criteria and Scores of each potential partner

Table 7: Relative closeness and ranking of potential partners using AHP-TOPSIS and F-AHP-TOPSIS

\begin{tabular}{|l|c|c|c|c|}
\hline & \multicolumn{3}{|c|}{ Relative Closeness } & \\
\hline $\begin{array}{l}\text { Potential } \\
\text { partners }\end{array}$ & AHP-TOPSIS & F-AHP-TOPSIS & Combined-TOPSIS & Final Ranking \\
\hline A1 & 0.234 & 0.453 & 0.313 & 3 \\
\hline A2 & 0.774 & 0.627 & 0.727 & 1 \\
\hline A3 & 0.391 & 0.380 & 0.384 & 2 \\
\hline
\end{tabular}

\subsection{Discussion of Results}

Two approaches are used to prioritise the evaluation criteria based on a current known scenario (AHP) and a future uncertain scenario (F-AHP) and then the criteria weights from these approaches are combined. The combined weights per criteria can be seen in Figure 3 next to each criterion. Figure 2 shows the changes in the weights between a known scenario using the AHP approach and an uncertain future scenario using the F-AHP approach. The risk criterion is judged the most important in both scenarios, however, its relative importance drastically decreases in the future scenario. This is because in the evaluation of the future scenario, equal priority is attributed to the economic and risk criteria. Conversely, in the AHP method, the risk criterion is considered three times more important than the economic pillar. The assumption is that risks at a future time may not be so impactful as a proper mitigation plan can be constructed once the partner is selected as part of the CNO. The final ranking using the AHP-TOPSIS methods, which is determined under the assumption that the conditions are known and therefore the prioritisation given to the criteria by the experts are crisp values, is different the F-AHP-TOPSIS method, in which the experts use fuzzy triangular numbers to attribute prioritisation between criteria. Based on the average of the criteria weights to determine the Combined weights, the final ranking ranks A2 first followed by A3, then A1.

Table 8 presents the sum of the weights of all criteria, the min and max and the standard deviation using the AHP and FAHP methods and their combined weights, as well as for the scores of the potential partners A1, A2 and A3. The range (max-min) of the weights for the scenario under uncertainty using F-AHP is less than half than the AHP method weights, even though all the weights add up to 1 . Similarly, the standard deviation of the scenario with known conditions is almost double than that of the unknown conditions. This is due to the decreased relative importance of the 
risk criterion compared to sustainability criteria for the future scenario, the assumption being that the risks can be mitigated fully or partially based on a plan developed by the CNO.

Table 8: Statistics of the Normalised weights of evaluation criteria using AHP and F-AHP and Scores of potential partners

\begin{tabular}{|l|l|l|l|l|l|l|}
\cline { 2 - 7 } \multicolumn{1}{c|}{} & \multicolumn{3}{c}{ Criteria Weights } & \multicolumn{3}{c|}{$\begin{array}{c}\text { Scoring of potential } \\
\text { partners }\end{array}$} \\
\cline { 2 - 8 } \multicolumn{1}{c|}{} & \multicolumn{1}{c|}{ AHP } & F-AHP & Combined & A1 & A2 & A3 \\
\hline Standard deviation & 0.043 & 0.024 & 0.029 & 0.877 & 0.934 & 0.828 \\
\hline Min & 0.002 & 0.000 & 0.001 & 2 & 2 & 2 \\
\hline Max & 0.218 & 0.093 & 0.139 & 5 & 5 & 5 \\
\hline Mean & 0.028 & 0.028 & 0.028 & 4.6 & 4.4 & 4.0 \\
\hline Sum & 1 & 1 & 1 & 164 & 158 & 144 \\
\hline
\end{tabular}

Looking into more detail at the criteria weights of a situation under known conditions using the AHP method, the top three most important criteria are the Customer Relationship Risk, Relational Risk and the Quality Risk. It makes sense that these are all part of the risk criterion as it has the most weight as in Figure 2. Conversely, the most important criteria for a future scenario are firstly, Force Majeure Risk, which relates to unforeseeable catastrophic future events such as the COVID pandemic and acts of god, followed by Environment Government requirements and Customer Relationship Risk. The Customer Relationship Risk remains in the highest weighted evaluation criteria in both scenarios. The Customer Relationship Risk includes the customer's ability or willingness to continue purchasing goods and is greatly impacted by external factors. Therefore, it maintains one of the highest weighting in the present time, due to known risks and circumstances, as well as in the future, based on unknown external factors, such as economic crises. The weight of the risk of a force majeure increases dramatically in the future scenario, making this criterion the most important of all. In the weighting of the criteria under known conditions, the Force Majeure Risk is considered less important than the six other risk factors in this pillar, however, in the future scenario under uncertainty, the importance of this risk overtakes the others. This criterion has the largest weight of all in the future scenario as its probability cannot be controlled by the $\mathrm{CNO}$ and the impact of the disaster is still widely unknown since the details of the disaster are unknown.

The combined AHP and F-AHP approach to determine criteria weights avoids the selection of the wrong partner. This is illustrated in Table 8 which compares the mean and total scores of the potential partners using the scoring method compared to their final ranking base on the approach proposed in this paper. If we only consider the scores given to each of the potential partners, A1 has the highest score followed by A2 and A3. However, when using the combined weights of the criteria under known and uncertain conditions, A2 ranks highest with the closest distance to the ideal solution followed by A3 and finally, A1 in last place. The TOPSIS ranking results using the combined AHP + F-AHP criteria weights, provides a much different result than using the individual weights. This is attributed to the scores of the partners for the most important criteria highlighting the importance to conscientiously weight the evaluation criteria. Omitting risk factors and a future crisis scenario, could result in wrong partner selection and issues in the case of a future pandemic-style scenario.

\section{Managerial Impact}

The Swiss State Secretariat for Economic Affairs (SECO) predicted that the manufacturing output from Switzerland would decrease by $25 \%$ in 2020 compared to 2019 due to the COVID pandemic. In October 2020, SECO's press release stated that the manufacturing industry in Switzerland has not recovered as much due to greater dependence on the global economic cycle (State Secretariat for Economic Affairs Switzerland, 2020). The survival of individual companies is heavily dependent on its capacity and capability in these times of crisis. Consequently, SMT can employ the method presented in this paper for the selection of new partners for the CNO. A CNO whose partners are selected based on current and future sustainability and risk requirements, can ensure resilience, longevity, and survival during such an unforeseeable event. The fact that SMT is a horizontal CNO provides an advantage for their ability to increase capacity and capabilities by working with various sourcing and logistics partners. This is particularly important in the case of CNO supply chain disruption as in the case of the COVID-19 pandemic as they should be better equipped to continue operational activities such as sourcing and logistics than if they worked as separate individual companies. 
The impact on the partner selection process of SMT is to integrate not only the three pillars of sustainability but also risk factors when considering the future longevity of the CNO under crisis. The methodology also identifies two important factors that are heavily linked to a global crisis: Customer Relationship Risk and the risk of a Force Majeure. Compared to the other 34 evaluation criteria, these interdependent criteria have the unique characteristic that their occurrence is ensured, however the severity of their impact is completely unknown and the control of the probability of occurrence is external to the CNO. Contrary to the other criteria, which the members of the CNO can manage and adjust. Consideration of these risk factors is therefore integral to correctly select future partners to ensure that SMT is not only competitive under relatively normal conditions, but also to ensure their survival in times of crisis.

\section{Conclusion}

Considering the devastating impact that the COVID-19 pandemic has had on the reliability of supply chains, logistics and sourcing worldwide, it is more important than ever to construct a solid network of organisations that collaborate for synergies as well as for the sake of the survival of the individual partner firms in times of crisis. This paper presents a novel approach, using AHP, F-AHP and TOPSIS, for sustainable partner selection for Collaborative Networked Organisations (CNO) that considers sustainability criteria and risk factors when evaluating potential companies under known current conditions and uncertain future scenarios.

The methodology is demonstrated on a Swiss CNO, Swiss Microtech (SMT) and identifies the risk criteria as the most influential factor in the selection of new partners, particularly the customer relationship risk and the risk of a force majeure, both of which are heavily influenced by external factors such as the COVID-19 pandemic. The results of the case study show that it is integral to evaluate partners based on known current conditions of their economic, social, environmental and risk criteria as well as under an uncertain future scenario that considers the occurrence of a force majeure such as a pandemic or act of god. Evaluating partners based on a future scenario, under the uncertainty of a global disaster, significantly impacts the weightings of all the evaluation criteria. The final ranking, however, remains stable, with potential partner A2 being ranked the best potential partner. The final ranking of potential partners using AHP for current conditions, F-AHP for future uncertain conditions and TOPSIS for final ranking, is also significantly different to the simple scoring method, where the potential partners are given a score per criterion and summed to give a total score per partner. Considering the relative importance of each criterion, as in the case of this paper, dramatically changes the final classification, yields a more appropriate ranking and avoid selecting the wrong partner.

The approach proposed in the paper is intended to support existing $\mathrm{CNO}$, as well as individual firms wanting to create a $\mathrm{CNO}$, to build a more robust and long lasting CNO in the context of a force majeure such as COVID-19. This is achieved by considering various sustainability criteria: economic, environmental, and social, and risk factors to evaluate potential partners, under both known current conditions and future uncertain conditions.

The limitation of the presented approach lies in the predicted evolution of criteria importance by the experts with regards to the future and in the face of gross uncertainty. Future research should focus on the interdependency of the evaluation criteria. As in the case of SMT, the customer relationship risk and the force majeure risk are highly interdependent as they are both influenced by the same external factors. Therefore, it is recommended to develop an ANP approach to take this interdependence into consideration and to determine whether the interdependence has a large impact on the final partner ranking.

Funding: This work was supported by the Swiss National Science Foundation under project $n^{\circ}$ [176349].

\section{References}

Abreu, A., Camarinha-Matos, L.M., 2008. On the role of value systems to promote the sustainability of collaborative environments. Int. J. Prod. Res. 46, 1207-1229. https://doi.org/10.1080/00207540701224244

Accenture, 2020. Supply chain disruption: State of supply chains [WWW Document]. Accenture. URL https://www.accenture.com/cr-en/insights/consulting/coronavirus-supply-chain-disruption (accessed 11.23.20). 
Arrais-Castro, A., Varela, M.L.R., Putnik, G.D., Ribeiro, R., Dargam, F.C.C., 2015. Collaborative Negotiation Platform using a Dynamic Multi-Criteria Decision Model. Int. J. Decis. Support Syst. Technol. IJDSST 7, 1-14. https://doi.org/10.4018/ijdsst.2015010101

Ashayeri, J., Tuzkaya, G., Tuzkaya, U.R., 2012. Supply chain partners and configuration selection: An intuitionistic fuzzy Choquet integral operator based approach. Expert Syst. Appl. 39, 3642-3649. https://doi.org/10.1016/j.eswa.2011.09.055

Ashtiani, B., Haghighirad, F., Makui, A., Montazer, G. ali, 2009. Extension of fuzzy TOPSIS method based on interval-valued fuzzy sets. Appl. Soft Comput. 9, 457-461. https://doi.org/10.1016/j.asoc.2008.05.005

Ayadi, O., Cheikhrouhou, N., Masmoudi, F., 2013. A decision support system assessing the trust level in supply chains based on information sharing dimensions. Comput. Ind. Eng. 66, 242-257. https://doi.org/10.1016/j.cie.2013.06.006

Ben Salah, S., Ben Yahia, W., Ayadi, O., Masmoudi, F., 2020. A Bilateral Multi-Attribute Negotiation-Based Approach for a VE Configuration. Group Decis. Negot. https://doi.org/10.1007/s10726-020-09686-y

Bhattacharya, R., Raut, R., Gardas, B., Kamble, S., 2020. Sustainable partner selection: an integrated AHP-TOPSIS approach. Int. J. Oper. Res. 39. https://doi.org/10.1504/IJOR.2020.10029296

Bierly, P.E., Gallagher, S., 2007. Explaining Alliance Partner Selection: Fit, Trust and Strategic Expediency. Long Range Plann. 40, 134-153. https://doi.org/10.1016/j.lrp.2007.03.001

Bozdağ, C.E., Kahraman, C., Ruan, D., 2003. Fuzzy group decision making for selection among computer integrated manufacturing systems. Comput. Ind. 51, 13-29. https://doi.org/10.1016/S01663615(03)00029-0

Camarinha-Matos, L.M., Afsarmanesh, H., Galeano, N., Molina, A., 2009. Collaborative networked organizations Concepts and practice in manufacturing enterprises. Comput. Ind. Eng., Collaborative e-Work Networks in Industrial Engineering 57, 46-60. https://doi.org/10.1016/j.cie.2008.11.024

Camarinha-Matos, L.M., Afsarmanesh, H., Ollus, M., 2008. Ecolead And Cno Base Concepts, in: Camarinha-Matos, Luis M., Afsarmanesh, Hamideh, Ollus, Martin (Eds.), Methods and Tools for Collaborative Networked Organizations. Springer US, Boston, MA, pp. 3-32. https://doi.org/10.1007/978-0-387-79424-2_1

Casady, C.B., Baxter, D., 2020. Pandemics, public-private partnerships (PPPs), and force majeure | COVID-19 expectations and implications. Constr. Manag. Econ. 38, 1077-1085. https://doi.org/10.1080/01446193.2020.1817516

Cheikhrouhou, N., Pouly, M., Huber, C., Beeler, J., 2012. Lessons learned from the lifecycle management of collaborative enterprises networks: The case of Swiss Microtech. J. Manuf. Technol. Manag. 23, 11291150. https://doi.org/10.1108/17410381211276907

Cheikhrouhou, N., Pouly, M., Madinabeitia, G., 2013. Trust categories and their impacts on information exchange processes in vertical collaborative networked organisations. Int. J. Comput. Integr. Manuf. 26, 87-100. https://doi.org/10.1080/0951192X.2012.681913

Chen, S., Lee, H., Wu, Y., 2008. Applying ANP approach to partner selection for strategic alliance. Manag. Decis. 46, 449-465. https://doi.org/10.1108/00251740810863889

Chen, T.-Y., Tsao, C.-Y., 2008. The interval-valued fuzzy TOPSIS method and experimental analysis. Fuzzy Sets Syst., Theme: Fuzzy Interval Analysis 159, 1410-1428. https://doi.org/10.1016/j.fss.2007.11.004

Chen, X., Riedel, R., Mueller, E., 2010. Evaluation on the technological innovation capability in companies based on the network, in: 2010 IEEE International Conference on Industrial Engineering and Engineering Management. Presented at the 2010 IEEE International Conference on Industrial Engineering and Engineering Management, IEEE, pp. 1324-1328. https://doi.org/10.1109/IEEM.2010.5674403

Choudhary, A.K., Harding, J.A., Tiwari, M.K., Shankar, R., 2019. Knowledge management based collaboration moderator services to support SMEs in virtual organizations. Prod. Plan. Control 30, 951-970. https://doi.org/10.1080/09537287.2019.1582102

Crispim, J.A., Pinho de Sousa, J., 2009. Partner selection in virtual enterprises: a multi-criteria decision support approach. Int. J. Prod. Res. 47, 4791-4812. https://doi.org/10.1080/00207540902847348

Cummings, J.L., Holmberg, S.R., 2012. Best-fit Alliance Partners: The Use of Critical Success Factors in a Comprehensive Partner Selection Process. Long Range Plann. 45, 136-159. https://doi.org/10.1016/j.lrp.2012.01.001

Das, T.K., Teng, B., 2000. A resource-based theory of strategic alliances. J. Manag. 31-60.

Dinu, S., Pacuraru, R., 2011. An intelligent modeling method based on genetic algorithm for partner selection in virtual organizations. Bus. Econ. Horiz. 5, 23-34. https://doi.org/doi:10.15208/beh.2011.12

Eccles, R.G., Serafeim, G., 2013. innovating for a sustainable strategy. Harv. Bus. Rev. 10. 
Garg, C.P., Sharma, A., 2020. Sustainable outsourcing partner selection and evaluation using an integrated BWMVIKOR framework. Environ. Dev. Sustain. 22, 1529-1557. https://doi.org/10.1007/s10668-018-0261-5

GRI 205: ANTI-CORRUPTION 2016, 2018.

GRI 413: LOCAL COMMUNITIES 2016, 2018.

Huang, B., Gao, C., Chen, L., 2011. Partner selection in a virtual enterprise under uncertain information about candidates. Expert Syst. Appl. 38, 11305-11310. https://doi.org/10.1016/j.eswa.2011.02.180

Huang, J.-J., Chen, C.-Y., Liu, H.-H., Tzeng, G.-H., 2010. A multiobjective programming model for partner selectionperspectives of objective synergies and resource allocations. Expert Syst. Appl. 37, 3530-3536. https://doi.org/10.1016/j.eswa.2009.09.044

Hwang, C.-L., Yoon, K., 2012. Multiple Attribute Decision Making: Methods and Applications A State-of-the-Art Survey. Springer Science \& Business Media.

Ip, W.H., Huang, M., Yung, K.L., Wang, D., 2003. Genetic algorithm solution for a risk-based partner selection problem in a virtual enterprise. Comput. Oper. Res. 30, 213-231. https://doi.org/10.1016/S03050548(01)00092-2

Jia, P., Govindan, K., Choi, T.-M., Rajendran, S., 2015. Supplier Selection Problems in Fashion Business Operations with Sustainability Considerations. Sustainability 7, 1603-1619. https://doi.org/10.3390/su7021603

Joshi, D., Kumar, S., 2016. Interval-valued intuitionistic hesitant fuzzy Choquet integral based TOPSIS method for multi-criteria group decision making. Eur. J. Oper. Res. 248, 183-191.

https://doi.org/10.1016/j.ejor.2015.06.047

Juergensen, J., Guimón, J., Narula, R., 2020. European SMEs amidst the COVID-19 crisis: assessing impact and policy responses. J. Ind. Bus. Econ. 47, 499-510. https://doi.org/10.1007/s40812-020-00169-4

Jung, K., 2017. Sources of Organizational Resilience for Sustainable Communities: An Institutional Collective Action Perspective. Sustainability 9, 1141. https://doi.org/10.3390/su9071141

Kafa, N., Hani, Y., Mhamedi, A.E., 2015. An integrated sustainable partner selection approach with closed-loop supply chain network configuration. IFAC-Pap., 15th IFAC Symposium onInformation Control Problems inManufacturing 48, 1840-1845. https://doi.org/10.1016/j.ifacol.2015.06.354

Kapucu, N., Hawkins, C.V., Rivera, F.I., 2012. Disaster Resiliency: Interdisciplinary Perspectives. Routledge, Abingdon, UK.

Kara, S.S., Ayadi, O., Cheikhrouhou, N., 2012. An Extensive Group Decision Methodology for Alliance Partner Selection Problem in Collaborative Networked Organisations. Int. J. Appl. Logist. IJAL 3, 1-19. https://doi.org/10.4018/jal.2012010101

Kara, S.S., Cheikhrouhou, N., 2014. A multi criteria group decision making approach for collaborative software selection problem. J. Intell. Fuzzy Syst. 26, 37-47. https://doi.org/10.3233/IFS-120713

Karsak, E.E., Kuzgunkaya, O., 2002. A fuzzy multiple objective programming approach for the selection of a flexible manufacturing system. Int. J. Prod. Econ., Theoretical Approaches and Decision Support 79, 101111. https://doi.org/10.1016/S0925-5273(00)00157-2

Labuschagne, C., Brent, A.C., 2005. Sustainable Project Life Cycle Management: the need to integrate life cycles in the manufacturing sector. Int. J. Proj. Manag. 23, 159-168. https://doi.org/10.1016/j.ijproman.2004.06.003

Luo, Z., Zhou, J., Li, Q., Liu, L., Yang, L., 2008. Partner Selection and Evaluation in Virtual Research Center Based on Trapezoidal Fuzzy AHP, in: Sun, F., Zhang, J., Tan, Y., Cao, J., Yu, W. (Eds.), Advances in Neural Networks ISNN 2008, Lecture Notes in Computer Science. Springer, Berlin, Heidelberg, pp. 110-118. https://doi.org/10.1007/978-3-540-87734-9_13

Macedo, P., Camarinha-Matos, L., 2017. Value Systems Alignment Analysis in Collaborative Networked Organizations Management. Appl. Sci. 7, 1231. https://doi.org/10.3390/app7121231

Memari, A., Dargi, A., Akbari Jokar, M.R., Ahmad, R., Abdul Rahim, Abd.R., 2019. Sustainable supplier selection: A multi-criteria intuitionistic fuzzy TOPSIS method. J. Manuf. Syst. 50, 9-24. https://doi.org/10.1016/j.jmsy.2018.11.002

Mikhailov, L., 2002. Fuzzy analytical approach to partnership selection in formation of virtual enterprises. Omega 30, 393-401. https://doi.org/10.1016/S0305-0483(02)00052-X

Mun, J., Shin, M., Lee, K., Jung, M., 2009. Manufacturing enterprise collaboration based on a goal-oriented fuzzy trust evaluation model in a virtual enterprise. Comput. Ind. Eng., Intelligent Manufacturing and Logistics 56, 888-901. https://doi.org/10.1016/j.cie.2008.09.022

Nielsen, B.B., Gudergan, S., 2012. Exploration and Exploitation Fit and Performance in International Strategic Alliances. Int. Bus. Rev. 21, 558-574. https://doi.org/10.1016/j.ibusrev.2011.07.001 
Önüt, S., Soner, S., 2008. Transshipment site selection using the AHP and TOPSIS approaches under fuzzy environment. Waste Manag. 28, 1552-1559. https://doi.org/10.1016/j.wasman.2007.05.019

Polyantchikov, I., Shevtshenko, E., Karaulova, T., Kangilaski, T., Camarinha-Matos, L.M., 2017. Virtual enterprise formation in the context of a sustainable partner network. Ind. Manag. Data Syst. 117, 1446-1468. https://doi.org/10.1108/IMDS-07-2016-0274

Quarantelli, E., Lagadec, P., Boin, A., 2007. A Heuristic Approach to Future Disasters and Crises: New, Old, and InBetween Types, in: Handbook of Disaster Research. Handbooks of Sociology and Social Research. Springer, New York, NY.

Rani, P., Mishra, A.R., Rezaei, G., 2020. Extended Pythagorean Fuzzy TOPSIS Method Based on Similarity Measure for Sustainable Recycling Partner Selection. Int. J. Fuzzy Syst. 22, 735-747. https://doi.org/10.1007/s40815-019-00689-9

Sarkis, J., Talluri, S., Gunasekaran, A., 2007. A strategic model for agile virtual enterprise partner selection. Int. J. Oper. Prod. Manag. 27, 1213-1234. https://doi.org/10.1108/01443570710830601

Seuring, S., 2013. A review of modeling approaches for sustainable supply chain management. Decis. Support Syst., Rapid Modeling for Sustainability 54, 1513-1520. https://doi.org/10.1016/j.dss.2012.05.053

Shah, R.H., Swaminathan, V., 2008. Factors influencing partner selection in strategic alliances: the moderating role of alliance context. Strateg. Manag. J. 29, 471-494. https://doi.org/10.1002/smj.656

Spreitzer, G., Porath, C.L., Gibson, C.B., 2012. Toward human sustainability: How to enable more thriving at work. Organ. Dyn., Applying a POS Lens to Bring out the Best in Organizations 41, 155-162. https://doi.org/10.1016/j.orgdyn.2012.01.009

State Secretariat for Economic Affairs Switzerland, 2020. Forecast: 2020 economic slump less serious than feared.

Talluri, S., Baker, R.C., 1996. A quantitative framework for designing efficient business process alliances, in: IEMC 96 Proceedings. International Conference on Engineering and Technology Management. Managing Virtual Enterprises: A Convergence of Communications, Computing, and Energy Technologies. Presented at the IEMC 96 Proceedings. International Conference on Engineering and Technology Management. Managing Virtual Enterprises: A Convergence of Communications, Computing, and Energy Technologies, pp. 656-661. https://doi.org/10.1109/IEMC.1996.547896

Tan, C., Zhang, Q., 2006. Fuzzy Multiple Attribute Decision Making Based on Interval Valued Intuitionistic Fuzzy Sets, in: 2006 IEEE International Conference on Systems, Man and Cybernetics. Presented at the 2006 IEEE International Conference on Systems, Man and Cybernetics, pp. 1404-1407. https://doi.org/10.1109/ICSMC.2006.384913

Verdecho, M.J., Alfaro-Saiz, J.J., Rodríguez-Rodríguez, R., 2010. An Approach to Select Suppliers for Sustainable Collaborative Networks, in: Camarinha-Matos, L.M., Boucher, X., Afsarmanesh, H. (Eds.), Collaborative Networks for a Sustainable World, IFIP Advances in Information and Communication Technology. Springer, Berlin, Heidelberg, pp. 304-311. https://doi.org/10.1007/978-3-642-15961-9_36

Wang, T.-C., Chen, Y.-H., 2007. Applying consistent fuzzy preference relations to partnership selection. Omega 35, 384-388. https://doi.org/10.1016/j.omega.2005.07.007

Wittstruck, D., Teuteberg, F., 2012. Integrating the concept of sustainability into the partner selection process: a fuzzy-AHP-TOPSIS approach. Int. J. Logist. Syst. Manag. 12, 195. https://doi.org/10.1504/IJLSM.2012.047221

Wu, C., Barnes, D., 2016. An integrated model for green partner selection and supply chain construction. J. Clean. Prod., Embedding Sustainability Dynamics in Supply Chain Relationship Management and Governance Structures 112, 2114-2132. https://doi.org/10.1016/j.jclepro.2015.02.023

Wu, N., Su, P., 2005. Selection of partners in virtual enterprise paradigm. Robot. Comput.-Integr. Manuf. 21, 119131. https://doi.org/10.1016/j.rcim.2004.05.006

Wu, W.Y., Shih, H.-A., Chan, H.-C., 2009. The analytic network process for partner selection criteria in strategic alliances. Expert Syst. Appl. 36, 4646-4653. https://doi.org/10.1016/j.eswa.2008.06.049

Xiao, J., Niu, Y., Chen, P., Leung, S.C.H., Xing, F., 2016. An improved gravitational search algorithm for green partner selection in virtual enterprises. Neurocomputing, SI: ALLSHC 217, 103-109. https://doi.org/10.1016/j.neucom.2016.03.092

Ye, F., 2010. An extended TOPSIS method with interval-valued intuitionistic fuzzy numbers for virtual enterprise partner selection. Expert Syst. Appl. 37, 7050-7055. https://doi.org/10.1016/j.eswa.2010.03.013

Ye, F., Lin, Q., 2014. Partner selection in a virtual enterprise: a group multiattribute decision model with weighted possibilistic mean values. Math. Probl. Eng. 
Yue, Z., 2013. An intuitionistic fuzzy projection-based approach for partner selection. Appl. Math. Model. 37, 9538-9551. https://doi.org/10.1016/j.apm.2013.05.007

Zhang, Y., Tao, F., Laili, Y., Hou, B., Lv, L., Zhang, L., 2013. Green partner selection in virtual enterprise based on Pareto genetic algorithms. Int. J. Adv. Manuf. Technol. 67, 2109-2125. https://doi.org/10.1007/s00170012-4634-x

Zhao, Q., Zhang, X., Xiao, R., 2008. Particle swarm optimization algorithm for partner selection in virtual enterprise. Prog. Nat. Sci. 18, 1445-1452. https://doi.org/10.1016/j.pnsc.2008.03.030

Zimmer, K., Fröhling, M., Schultmann, F., 2016. Sustainable supplier management - a review of models supporting sustainable supplier selection, monitoring and development. Int. J. Prod. Res. 54, 1412-1442. https://doi.org/10.1080/00207543.2015.1079340 